\title{
Psychometric assessment of the Behavior and Attitudes Questionnaire for Healthy Habits: measuring parents' views on food and physical activity
}

\author{
Beverly W Henry ${ }^{1, *}$, Thomas J Smith ${ }^{2}$ and Saadia Ahmad ${ }^{1}$ \\ 'School of Family, Consumer, and Nutrition Sciences, Northern Illinois University, DeKalb, IL 601 15, USA: \\ ${ }^{2}$ Department of Educational Technology, Research and Assessment, College of Education, Northern Illinois \\ University, DeKalb, IL, USA
}

Submitted 3 May 2012: Final revision received 20 November 2012: Accepted 2 December 2012: First published online 18 January 2013

\begin{abstract}
Objective: To assess parents' perspectives of their home environments to establish the validity of scores from the Behavior and Attitudes Questionnaire for Healthy Habits (BAQ-HH).

Design: In the present descriptive study, we surveyed a cross-sectional sample of parents of pre-school children. Questionnaire items developed in an iterative process with community-based programming addressed parents' knowledge/ awareness, attitudes/concerns and behaviours about healthy foods and physical activity habits with 6-point rating scales. Exploratory and confirmatory factor analyses were used to psychometrically evaluate scores from the scales.

Setting: English and Spanish versions of the BAQ-HH were administered at parent-teacher conferences for pre-school children at ten Head Start centres across a five-county agency in autumn 2010.

Subjects: From 672 families with pre-school children, 532 parents provided responses to the BAQ-HH (79\% response rate). The majority was female ( $83 \%)$, Hispanic (66\%) or white (16\%), and ages ranged from 20 to 39 years (85\%).

Results: Exploratory and confirmatory analyses revealed a knowledge scale (seven items), an attitude scale (four items) and three behaviour subscales (three items each). Correlations were identified between parents' perceptions of home activities and reports of children's habits. Differences were identified by gender and ethnicity groupings.

Conclusions: As a first step in psychometric testing, the dimensionality of each of the three scales (Knowledge, Attitudes and Behaviours) was identified and scale scores were related to other indicators of child behaviours and parents' demographic characteristics. This questionnaire offers a method to measure parents' views to inform planning and monitoring of obesity-prevention education programmes.
\end{abstract}

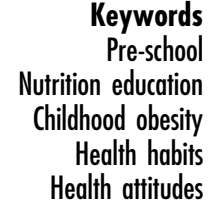

Keywords utrition education Health habits Health attitudes
Despite efforts to reduce the proportion of people in the USA affected by overweight and obesity, childhood obesity continues to be a major concern ${ }^{(1)}$. Data from the National Health and Nutrition Examination Survey show that the obesity trends extend to pre-school children (aged 2-5 years), with prevalence rates doubling between 1976-1980 and 2007-2008 from 5.0\% to $10 \cdot 4 \%{ }^{(2)}$. Even more concerning, trends among children of different ethnicities and income levels demonstrate significant disparities. For example, overweight status among preschool boys ranged from $21 \cdot 0 \%$ among Caucasians to $28 \cdot 1 \%$ among Non-Hispanic blacks and 30.7\% among Hispanics $^{(2)}$. On the 2009 Pediatric Nutrition Surveillance System, the prevalence rate among low-income children in the USA reached one in three being overweight or obese before their fifth birthday ${ }^{(3)}$. Problems associated with childhood overweight include health risks and increased difficulty maintaining a healthy weight in later years $^{(4-7)}$. The relevance of early childhood to lifelong health trajectory denotes the life course model signified by early-life events playing an important role in shaping an individual's health status and general well-being ${ }^{(8)}$.

Even with the overweight/obese status among minorities and descriptions of low-income neighbourhoods as obesogenic environments ${ }^{(9)}$, there is evidence that a focus on parents can make a difference. The American Heart Association emphasized evaluating parents as 'agents of change' for childhood obesity and strategies to improve feeding practices and the home environment, while highlighting gaps in the research ${ }^{(10)}$. Parents foster 
children's development of eating behaviours through means such as making decisions about food choices and also role modelling them ${ }^{(11-14)}$. In research by Pinard et al., correlations between habitual beverage intake in parentchild dyads highlighted parents' role as gatekeepers of the home food environment ${ }^{(15)}$. Parent education about healthy food choices and helpful suggestions for daily living in the midst of common concerns are recommended to encourage positive health behaviour from the beginning of a child's life, and has shown a positive impact in settings such as child care and Head Start ${ }^{(16-18)}$. The Head Start federally funded child development programme includes parent education in a multilevel approach to support lowincome families in overcoming the challenges they face and to optimize the influence parents have on the health status of their children ${ }^{(18)}$

While health educators aim to decrease children's risk for overweight status through nutrition education, knowledge-based programming alone tends to have a weak relationship with behaviour change ${ }^{(19,20)}$. Understanding basic facts about healthy food choices or instrumental knowledge can meet a need for knowing what a healthy choice would be (e.g. portion sizes or the amount of sugar in foods); but it is a big leap to assume knowledge alone will lead to overcoming barriers to behaviour change. One theoretical framework commonly used when planning nutrition interventions is the knowledge-attitude-behaviour (KAB) model, which suggests that as people acquire health and nutrition knowledge, their attitudes may be affected (e.g. motivation or rating of importance) and can lead to a positive result on behaviour change ${ }^{(20,21)}$. In a study of food label use among college students, attitude measures (i.e. agreement that food labels were useful, accurate and truthful) were found to mediate the relationship between knowledge and behaviour ${ }^{(22)}$. Researchers have also considered other frameworks with KAB-framed interventions among different groups, such as the transtheoretical model $^{(23)}$ and self-efficacy constructs ${ }^{(24,25)}$. Despite the availability of parent questionnaires to assess nutrition education, a systematic review by Pinard et al. showed that use of these tools is limited by the lack of psychometric assessment and the topic thus merits further research ${ }^{(26)}$.

Current literature offers examples of specific content to consider for programming with parents to influence health habits in the home ${ }^{(10,19,26)}$. An instrument to assess domains of interest through parental report of potential influences on young children's health habits in the home environment could support such programming. To meet this need, the Behavior and Attitudes Questionnaire for Healthy Habits (BAQ-HH) was designed by a community coalition for use during interventions for parents of elementary-school children. The purpose of the present study was to establish evidence of the validity of scores from the BAQ-HH in a cross-sectional sample of parents of pre-school children. As a first step in psychometric testing, assessment of the dimensionality of each of the three scales (entitled Knowledge, Attitudes and Behaviours) was conducted. Second, the scale scores were related to other indicators of child behaviours and the demographic characteristics of respondents. Assessing questionnaire items to reflect healthy habits within the home environment, from role modelling and food rules to food availability and accessibility, may support planning and monitoring of educational interventions to parents of young children.

\section{Methods}

The current cross-sectional, descriptive study aimed to describe the development and use of the BAQ-HH among a sample of parents. The Northern Illinois University and the Two Rivers Head Start Agency approved the study and parents voluntarily completed the questionnaire (or not) and remained anonymous if desired. Guidelines for the use of human subjects in research were strictly adhered to during the study, and the researchers had access to de-identified data only. Parent self-report of demographic information was used to compare with the Head Start Agency statistics and to assess survey response patterns.

\section{Population and sample}

The target population consisted of parents or guardians (referred to as 'parents' from this point forward) from 672 families enrolled in ten Head Start centres during the academic year 2010-2011. Part of a federally funded child development programme, the Two Rivers Head Start Agency provides services for families and their pre-school children (aged 3-5 years) who are affected by poverty ${ }^{(27)}$. The programme aims to alleviate the effects of poverty by providing education, support services and opportunities for children, families and communities, and involves the parent as primary educator. From the 672 families, a total of 532 parents of pre-school children (each from a unique family) participated in the survey.

\section{Instrument development}

The content areas addressed on the BAQ-HH were determined through an iterative process with representatives from community health agencies (see Table 1). A community coalition of members from schools, health care, higher education and recreation activities considered these three key areas to be fundamental for monitoring of programme implementation that matched with behavioural change models ${ }^{(19)}$. Although researchers may adapt an instrument with revision and adding of pertinent items as needed ${ }^{(22,23,25)}$, item generation for the BAQ-HH relied on multiple surveys ${ }^{(28)}$. A list of items was extracted from existing surveys identified through a structured search of peer-reviewed literature ${ }^{(11,29-33)}$ and 
Table 1 Content areas to monitor parents' responses

Knowledge: causes and prevention of obesity
Portion sizes
Amount of sugar and fat in foods
Foods to have at home
Physical activities
Attitudes: concerns about healthy choices at home
Promoting energy balance
Barriers to healthy habits
Behaviours: eating, physical activity and health promotion
Food choices
Mealtimes
Communicating healthy messages

public health promotion materials ${ }^{(34,35)}$. The list included statements associated with health issues ${ }^{(31,33,34)}$, parental control of child feeding ${ }^{(11,29,30)}$ and aspects of the home environment ${ }^{(11,30,32,33,35)}$. In multiple cases, extracted items were found on more than one source as also noted by Pinard et $a l^{(26)}$ in their systematic review which revealed overlapping constructs assessed on different measures.

Over a 2-year period, coalition members periodically reviewed results from multiple trials of the questionnaire at after-school programming to assess item content for relevance and utility. Also, they compared survey results with verbal comments from parents. During this process, coalition members suggested modifications to match items with routine health programming and dietary guidelines, revised wording to enhance clarity in response to parents' questions and removed sixteen items from the original list of forty-two (leaving twenty-six items remaining) for the following reasons: redundancy, a ceiling effect, and discordance about positive interpretation of parents' responses such as drinking fruit juice (better than fruit drinks, not as good as whole fruits). While the questionnaire was designed in English, a hospital-based language service translated questionnaire items into Spanish and also back-translated the final Spanish version into English without any problems identified. Both versions of items were distributed (English text on the front side, Spanish text on the back side of each page).

\section{Pilot testing}

For the present validation study, the proposed version of the BAQ-HH was pilot-tested with a convenience sample of ninety-four parents from nine elementary schools in the Elgin area, one of the communities served by the Two Rivers Head Start Agency. Results showed adequate internal consistency reliability for scores from the knowledge and attitude scales, with Cronbach's $\alpha$ values of 0.91 and 0.86 , respectively. However, internal consistency of scores from the behaviour scale was low, with $\alpha=0 \cdot 23$. We attributed this to confusing response options and the potential for different factors within this section. Thus, response options for the behaviour items were revised. Rao's survey on the 'Big Five' common child behaviours linked to the development of obesity ${ }^{(36)}$, i.e. drinking sweetened beverages, eating fast food, eating dinner with a parent, having screen time and being active, was also administered for comparison with parent views on the BAQ-HH. Rao pilot-tested this screening tool in a large number of community practices in western Pennsylvania ${ }^{(36)}$. Prior to use, local health education professionals reviewed the final version of the BAQ-HH in both languages for completion time (average $10 \mathrm{~min}$ ) and utilization with parents of pre-school children, deeming it acceptable on both counts.

\section{Data collection}

Teachers and staff distributed the BAQ-HH for parents to complete when attending parent-teacher conferences. Parents were directed to think about food and physical activity for their family and respond accordingly. Questionnaire items addressed three content areas (see Table 1) with varied response options and were mixed on positive and negative wording. For the seven items pertaining to knowledge (i.e. awareness) of health habits, parents were asked to indicate their level of agreement ('strongly disagree' to 'strongly agree'). The four items reflecting parentts' attitudes related to behaviour changes asked parents to indicate their level of agreement ('strongly disagree' to 'strongly agree') with specific statements. Thus, higher ratings indicated more concern, an undesirable response. Responses on the fifteen behaviour items indicated how often ('never' to 'always') they practised positive health behaviours at home. These items addressed the home food environment, role modelling and health messages. (A copy of the BAQ-HH is available from the authors upon request.) In addition, we included five items adopted from the 'Big Five' prompting parental report of children's behaviours, demographic items and two open-ended questions to solicit comments about parent-perceived barriers and opportunities to improve health habits.

\section{Data analysis}

To assess the construct validity of scores from the BAQ-HH, both exploratory factor analysis and confirmatory factor analysis were carried out using the statistical software packages SPSS version $19 \cdot 0$ and MPLUS version $6 \cdot 12$, respectively. A development sample was first constructed, consisting of one-half of the cases ( $n$ 266), randomly selected. These cases were used to fit unidimensional confirmatory models to the attitude and knowledge items. Pairwise deletion of missing values was employed. Because no a priori structure was identified for the behaviour scale, an exploratory factor analysis (using principal axis factoring and promax rotation) was carried out for these items. The number of factors was determined using Kaiser's rule (number of eigenvalues $>1 \cdot 0$ ), examination of the scree plot and a parallel analysis ${ }^{(37)}$. The ratio of the number of cases to the number of indicators $(n / p)$ for the exploratory factor analysis carried 
out on the behavioural subcale was $26: 1$. The ratio of the number of cases to the number of parameters $(n / q)$ for the confirmatory factor analysis was 11:1, 18:1 and 8:1 for the knowledge, attitude and behaviour scales, respectively. Due to strong skewness in the distributions of scores, robust maximum likelihood estimation was used for the confirmatory analyses. Because significance of the $\chi^{2}$ statistic is highly influenced by the large sample size, goodness-of-fit was assessed using the comparative fit index (CFI), the Tucker-Lewis index (TLI), the root-mean error of approximation (RMSEA) and the standardized root-mean residual (SRMR). Criteria used were CFI, TLI $>0 \cdot 95, \quad$ SRMR $<0 \cdot 05$ and RMSEA $<0 \cdot 06^{(38,39)}$. The remaining cases in the data set ( $n$ 266) were then used to cross-validate the models identified with the development sample, using confirmatory factor analysis.

\section{Results}

From the parent-teacher conferences at ten Head Start centres, 532 parents submitted questionnaires for a $79 \%$ response rate. Response rates per centre ranged from $35 \%$ to $97 \%$ of families enrolled (average response rate $72 \%)$ and reasons for non-response were not recorded. All completed questionnaires were included in analysis and missing or unclear values were coded accordingly. All response patterns are reported as valid percentages for ease of data interpretation.

Demographic characteristics of parent respondents are shown in Table 2. As expected, mothers made up the majority of participants. Also, the majority indicated Hispanic ethnicity and the BAQ-HH Spanish version was completed by $271(56 \%)$ participants. Ethnicity can be compared with Agency statistics which reported the following for their total enrolment: $16 \%$ black, $11 \%$ white, $63 \%$ Hispanic, $<1 \%$ Asian and 10\% other/unspecified/multiple. Also, the Agency reported nineteen children being cared for by non-parent guardians. Most participants reported their age to be in the range from 20 years to 39 years (85\%), and selection of education levels was largely distributed between grade school and some college.

\section{Psychometric testing}

When a single-factor model was fitted to the attitude items using the first random sample of cases, results showed a good fit of the model to the data on three of the four indices with CFI $=0.99, \mathrm{TLI}=0 \cdot 99, \mathrm{SRMR}=0 \cdot 01$ and RMSEA $=0.06\left(\chi^{2}(6, n\right.$ 237 $\left.)=424 \cdot 92, \quad P<0 \cdot 01\right)$. This model was cross-validated with the second random sample, with $\mathrm{CFI}=1 \cdot 00$, TLI $=0 \cdot 99$, SRMR $<0 \cdot 01$ and RMSEA $=0 \cdot 03\left(\chi^{2}(6, n 237)=392 \cdot 17, P<0 \cdot 01\right.$; see Table 3$)$. Similarly, a single-factor model fitted to the knowledge items demonstrated good fit, with CFI $=0.99$, TLI $=0.99$, SRMR $=0.03$ and RMSEA $=0.03\left(\chi^{2}(21, n 242)=534.30\right.$, $P<0 \cdot 01)$. This result with the knowledge items was
Table 2 Demographic characteristics of respondents to the BAQ-HH: parents ( $n$ 532) of pre-school children aged $2-5$ years enrolled in ten Head Start centres, USA, autumn 2010

\begin{tabular}{lrr}
\hline & Frequency & $\%$ \\
\hline Gender of reporting parent & & \\
Female & 441 & 83 \\
Male & 63 & 12 \\
Unspecified & 28 & 5 \\
Ethnicity & & \\
Black & 49 & 9 \\
White & 87 & 16 \\
Hispanic & 351 & 66 \\
Asian & 7 & 1 \\
Other/unspecified & 38 & 7 \\
Age & & 2 \\
18-20 years old & 8 & 47 \\
20-29 years old & 251 & 38 \\
30-39 years old & 201 & 8 \\
40-49 years old & 43 & $<1$ \\
50-59 years old & 5 & 4 \\
60 years old or above & 3 & \\
Unspecified & 21 & 20 \\
Highest level of education & & 22 \\
Grade school & 109 & 23 \\
Some high school & 118 & 18 \\
High-school graduate & 120 & 8 \\
Some college & 92 & 9 \\
College degree & 41 & 5 \\
Graduate school/post & 5 & \\
Unspecified & 46 & \\
\hline
\end{tabular}

BAQ-HH, Behavior and Attitudes Questionnaire for Healthy Habits.

cross-validated with the second random sample, with CFI $=0.98$, TLI $=0 \cdot 97$, SRMR $=0.03$ and RMSEA $=0.04$ $\left(\chi^{2}(21, n 235)=349 \cdot 03, P<0 \cdot 01\right)$. Table 3 provides loading estimates.

Because no a priori structure was posited for the fifteen behaviour items, an exploratory factor analysis was carried out using the first random sample of cases (see Table 4). Using Kaiser's rule (number of eigenvalues $>1 \cdot 0$ ), examination of the scree plot and a parallel analysis ${ }^{(37)}$, a three-factor solution was indicated. Based on factor loadings and substantive evaluation, six items were eliminated, resulting in nine behaviour items. Removed items included frequency of 'unhealthy' behaviours, parents' physical activity and snacking. The posited structure of these nine items was next cross-validated using the second random sample of cases. A three-factor correlated factor structure, with each factor consisting of three items, was fitted (see Table 5) and the model fit was good, with $\mathrm{CFI}=0.99, \quad \mathrm{TLI}=0.98, \quad \mathrm{SRMR}=0.03$ and RMSEA $=0.04\left(\chi^{2}(36, n 236)=556.79, P<0.01\right)$. Reliability indices (Cronbach's $\alpha$ ) for the subscales were 0.87 (Knowledge), 0.83 (Attitudes), 0.60 (Decision-Making), 0.75 (Mealtime) and 0.82 (Communication).

Finally, to address discrimination between scales, confirmatory factor analysis was carried out using all items simultaneously (nine knowledge, four attitude and nine behaviour items) and using the entire sample of cases. Three factors were specified (knowledge, attitudes, behaviour), with three additional primary factors subsumed 
under the single, secondary behaviour factor. A correlated factor model with simple structure was posited. Results showed an adequate model fit on two indices, CFI $=0.95$ and RMSEA $=0.05\left(\chi^{2}(220, n 394)=383 \cdot 47, P<0 \cdot 01\right)$, while the observed values of TLI $=0.94$ and $\mathrm{SRMR}=0.06$ approached their fit criteria.

Scores for the knowledge, attitude and behaviour scales were next computed (using the sum of the item scores for each). Spearman correlations between each of these subscales and the (ordinally scored) 'Big Five' items in an abbreviated format are shown in Table 6. Table 6 also shows the Pearson correlations between each of the BAQ-HH subscales and the 'Big Five' total scores. For the total 'Big Five' score, low level correlations with each of the BAQ-HH scales were evident $(P<0 \cdot 01)$, except for the Attitudes scale $(P=0 \cdot 53)$.

We next examined whether knowledge, attitudes and behaviour differed by gender or ethnicity. Due to small sample sizes for ethnicities other than 'black', 'white' and 'Hispanic', only these three ethnic groups were compared. Table 7 shows descriptive statistics for the subscale score averages by gender and ethnicity. For gender, results showed that females scored significantly higher than males for Decision-Making $(F(1,497)=9 \cdot 92$, $P<0 \cdot 01)$ and Mealtime $(F(1,497)=5 \cdot 73, \quad P=0.02)$. Significant ethnic differences in scores were evident for Attitudes $(F(2,479)=36 \cdot 32, P<0 \cdot 01)$, Decision-Making $(F(2,479)=48.91, \quad P<0.01)$ and Communication $(F(2,476)=28 \cdot 63, P<0 \cdot 01)$. Tukey post hoc pairwise comparisons of attitude scores indicated that Hispanic parents showed greater concern about health habits than either white parents $(P<0 \cdot 01)$ or black parents $(P<0 \cdot 01)$, while attitude scores for black parents and white parents did not differ significantly $(P=0 \cdot 50)$. For the DecisionMaking subscale, white parents showed significantly higher scores than Hispanic parents $(P=0 \cdot 04)$; while for the Communication subscale, Hispanic parents showed significantly higher scores than white parents $(P<0 \cdot 01)$ or black parents $(P<0 \cdot 01)$, and white parents showed significantly higher scores than black parents $(P=0 \cdot 02)$. No other significant differences were evident.

Additional analysis was carried out to identify associations between parent characteristics and survey responses. Spearman correlations indicated that parental age was significantly and positively related to concern about child health habits $\left(r_{s}=0 \cdot 13, P<0 \cdot 01\right)$. Parental schooling was positively related to Decision-Making $\left(r_{s}=0 \cdot 16, P<0 \cdot 01\right)$, but negatively related to concern $\left(r_{s}=-0 \cdot 21, P<0 \cdot 01\right)$ and Communication $\left(r_{s}=-0 \cdot 13, P<0 \cdot 01\right)$. Other associations were not statistically significant.

\section{Discussion}

Findings from the current study offer validity evidence for the use of the BAQ-HH to solicit parents' views about 
Table 4 Factor loadings based on exploratory factor analysis of the behaviour items of the BAQ-HH among parents ( $n$ 532) of pre-school children aged 2-5 years enrolled in ten Head Start centres, USA, autumn 2010

\begin{tabular}{|c|c|c|c|}
\hline Item & Factor 1 & Factor 2 & Factor 3 \\
\hline \multicolumn{4}{|l|}{ I usually... } \\
\hline decide my child's portion sizes & 0.57 & 0.07 & $-0 \cdot 18$ \\
\hline decide if my child is eating healthy foods & $0 \cdot 66$ & 0.04 & $-0 \cdot 15$ \\
\hline ask about what my child eats at school & 0.63 & $-0 \cdot 21$ & 0.07 \\
\hline let my child snack between meals & 0.57 & $-0 \cdot 36$ & 0.04 \\
\hline let my child watch TV between meals & $-0 \cdot 23$ & 0.51 & $-0 \cdot 26$ \\
\hline serve meals at a regular time & 0.23 & 0.49 & 0.06 \\
\hline serve fruits and vegetables with meals & $0 \cdot 30$ & 0.38 & $0 \cdot 18$ \\
\hline eat meals with my child & 0.03 & $0 \cdot 61$ & $0 \cdot 10$ \\
\hline use food to reward my child for good behaviour & $0 \cdot 13$ & $0 \cdot 06$ & -0.34 \\
\hline join my family in physical activity & $0 \cdot 00$ & 0.39 & 0.40 \\
\hline encourage my child to eat breakfast & 0.02 & 0.33 & 0.38 \\
\hline talk about the value of a healthy diet & 0.09 & $-0 \cdot 21$ & $0 \cdot 82$ \\
\hline push my child to play outside & 0.01 & -0.23 & $0 \cdot 87$ \\
\hline talk about the value of physical activity & $-0 \cdot 08$ & $-0 \cdot 13$ & 0.95 \\
\hline join my child in outdoor and play activities & $-0 \cdot 15$ & 0.43 & 0.51 \\
\hline
\end{tabular}

BAQ-HH, Behavior and Attitudes Questionnaire for Healthy Habits; TV, television.

The response options for this section were based parents' estimates of the frequency that they did these behaviours with a 6-point response scale: 1 = 'never'; 2 = 'rarely'; 3 = 'occasionally'; 4 = 'often'; 5 = 'very often'; 6 = 'always'.

Table 5 Factor loadings (and robust standard errors) based on confirmatory factor analysis of the behaviour scale of the BAQ-HH among parents $(n 532)$ of pre-school children aged $2-5$ years enrolled in ten Head Start centres, USA, autumn 2010

\begin{tabular}{|c|c|c|c|c|c|c|}
\hline \multirow[b]{2}{*}{ Item } & \multicolumn{2}{|c|}{ Factor 1 loading } & \multicolumn{2}{|c|}{ Factor 2 loading } & \multicolumn{2}{|c|}{ Factor 3 loading } \\
\hline & Mean & SE & Mean & SE & Mean & SE \\
\hline \multicolumn{7}{|l|}{ I usually... } \\
\hline decide my child's portion sizes & $0 \cdot 60$ & 0.07 & & & & \\
\hline decide if my child is eating healthy foods & $0 \cdot 72$ & 0.06 & & & & \\
\hline ask about what my child eats at school & 0.46 & 0.08 & & & & \\
\hline serve meals at a regular time & & & 0.78 & 0.05 & & \\
\hline serve fruits and vegetables with meals & & & 0.73 & 0.06 & & \\
\hline eat meals with my child & & & 0.65 & 0.08 & & \\
\hline talk about the value of a healthy diet & & & & & 0.74 & 0.05 \\
\hline push my child to play outside & & & & & $0 \cdot 76$ & 0.05 \\
\hline talk about the value of physical activity & & & & & 0.90 & 0.03 \\
\hline
\end{tabular}

BAQ-HH, Behavior and Attitudes Questionnaire for Healthy Habits.

Terms used to describe the three behaviour subscales were: $1=$ Decision-Making; $2=$ Mealtime; $3=$ Communication.

Table 6 Correlations between the BAQ-HH scales and the BF item scores among parents $(n 532)$ of pre-school children aged $2-5$ years enrolled in ten Head Start centres, USA, autumn 2010

\begin{tabular}{|c|c|c|c|c|c|}
\hline BF item & Knowledge & Attitudes & Decision-Making & Mealtime & Communication \\
\hline $\begin{array}{l}\text { BF1: Servings of sweetened drinks daily } \\
\text { BF2: Frequency of fast food eaten weekly } \\
\text { BF3: Frequency of dinner with a parent weekly } \\
\text { BF4: Time spent viewing television or computer daily } \\
\text { BF5: Frequency that activity reaches at least } 30 \text { min weekly } \\
\text { BF total score (range } 0-100 \text { ) }\end{array}$ & $\begin{array}{l}-0 \cdot 22^{\star *} \\
-0 \cdot 14^{\star *} \\
0 \cdot 10^{\star} \\
-0 \cdot 04 \\
0 \cdot 11^{\star} \\
0 \cdot 16^{\star \star}\end{array}$ & $\begin{array}{l}-0.08 \\
-0.08 \\
-0 \cdot 15^{\star \star} \\
-0.06 \\
-0 \cdot 16^{\star \star} \\
-0.03\end{array}$ & $\begin{array}{l}-0 \cdot 13^{\star \star} \\
-0.08 \\
0 \cdot 17^{\star \star} \\
-0.02 \\
0 \cdot 17^{\star \star} \\
0 \cdot 22^{\star \star}\end{array}$ & $\begin{array}{l}-0.05 \\
-0.03 \\
0.22^{\star \star} \\
-0.08 \\
0 \cdot 15^{\star \star} \\
0.23^{\star \star}\end{array}$ & $\begin{array}{l}-0 \cdot 18^{\star \star} \\
-0 \cdot 12^{\star \star} \\
-0 \cdot 01 \\
-0 \cdot 11^{\star} \\
0 \cdot 01 \\
0 \cdot 15^{\star \star}\end{array}$ \\
\hline
\end{tabular}

BAQ-HH, Behavior and Attitudes Questionnaire for Healthy Habits; BF, 'Big Five'.

High scores on BF items BF1, BF2 and BF4 indicate unhealthy habits; high scores on BF items BF3, BF5 and BF total score indicate healthy habits.

${ }^{\star} P<0 \cdot 05,{ }^{* \star} P<0 \cdot 01$.

healthy habits in the home environment. Confirmatory factor analysis suggested good fit of a single-factor model for both the attitude and the knowledge items and a three-factor correlated factor structure of behaviour items from these low-income parents of pre-school children. Although only nine of fifteen behaviour-related questions remained after analysis, these items showed good psychometric properties and reflected three types of parenting behaviour that we fit under decision-making, mealtime and communication behaviours. The survey items included indicators of the food and physical activity in the home as well as the social or physical environment as described in the systematic review by Pinard et al. ${ }^{(26)}$. 
Table 7 Descriptive statistics for BAQ-HH scales by gender and ethnicity: parents ( $n$ 532) of pre-school children aged $2-5$ years enrolled in ten Head Start centres, USA, autumn 2010

\begin{tabular}{|c|c|c|c|c|c|c|c|c|}
\hline Scale & Gender & $n$ & Mean & SD & Ethnicity† & $n$ & Mean & SD \\
\hline \multirow[t]{3}{*}{ Attitudes } & Male & 62 & 3.66 & $1 \cdot 38$ & Black & 49 & $2 \cdot 42$ & $1 \cdot 17$ \\
\hline & Female & 437 & 3.39 & 1.52 & Hispanic & 347 & 3.80 & 1.49 \\
\hline & & & & & White & 86 & $2 \cdot 70$ & $1 \cdot 12$ \\
\hline \multirow[t]{3}{*}{ Knowledge } & Male & 62 & 5.09 & 0.95 & Black & 49 & 4.94 & $1 \cdot 13$ \\
\hline & Female & 439 & $5 \cdot 18$ & 0.89 & Hispanic & 348 & $5 \cdot 19$ & 0.92 \\
\hline & & & & & White & 86 & 5.08 & 0.92 \\
\hline \multirow[t]{3}{*}{ Decision-Making } & Male & 62 & $4 \cdot 31$ & $1 \cdot 28$ & Black & 49 & $5 \cdot 00$ & 0.90 \\
\hline & Female & 439 & $4 \cdot 77$ & 1.03 & Hispanic & 347 & $4 \cdot 63$ & $1 \cdot 11$ \\
\hline & & & & & White & 86 & $4 \cdot 94$ & 0.97 \\
\hline \multirow[t]{3}{*}{ Mealtime } & Male & 62 & $4 \cdot 77$ & $1 \cdot 08$ & Black & 49 & 4.93 & 0.95 \\
\hline & Female & 438 & 5.07 & 0.89 & Hispanic & 346 & 4.99 & 0.97 \\
\hline & & & & & White & 86 & $5 \cdot 21$ & 0.74 \\
\hline \multirow[t]{3}{*}{ Communication } & Male & 62 & $4 \cdot 57$ & 1.33 & Black & 49 & 3.76 & $1 \cdot 17$ \\
\hline & Female & 437 & $4 \cdot 69$ & $1 \cdot 24$ & Hispanic & 344 & 4.95 & $1 \cdot 16$ \\
\hline & & & & & White & 86 & $4 \cdot 31$ & $1 \cdot 17$ \\
\hline
\end{tabular}

BAQ-HH, Behavior and Attitudes Questionnaire for Healthy Habits.

The total score for each scale is scored as the mean of the item scores on a 6-point scale.

tEthnicity includes the top three groups representing $91 \%$ of parents who provided this information.

As intended, the three content areas met community goals to align with the KAB model for information awareness, concern and parent actions representing knowledge, attitudes and behaviours, respectively. Of the three behavioural scales, decision-making demonstrated lower internal consistency $(\alpha=0 \cdot 60)$ possibly due to parents' perceived lower control of food choices at school $v$. home. The BAQ-HH items and resulting subscales may function as indicators of parents' knowledge of health issues, attitudes and behaviours with child feeding or aspects of the home environment that typically fall under the parent's direction. Further evidence of psychometric properties of each scale, including predictive validity and generalizability, is needed.

The response rate of $79 \%$ denotes a good level of sampling from this population of low-income families with children of pre-school age served by Head Start programming across five counties. The majority of respondents were female ( $88 \%)$. Also, Hispanic was the most frequently reported ethnicity $(66 \%)$ and represents a high-risk population. These results suggest that this group of parents was in agreement with statements related to health concerns at the start; however, as noted by Baranowski et al. ${ }^{(19)}$, prevailing attitudes or concerns may limit implementation of recommended behaviour changes. Also, the transtheoretical approach may enhance community programming with consideration of self-efficacy or readiness to change as noted by others ${ }^{(23-25)}$.

Analysis of the BAQ-HH data revealed correlations between the behaviour subscale scores and parent report on 'Big Five' items. Specifically, parents' behaviour scores were associated with responses on each of the 'Big Five' items (with positive behaviour scores coinciding with positive 'Big Five' child behaviour patterns). This preliminary observation suggests consistency between parents' report of their own behaviours and their reports of their children's behaviours. Prior research concerning beverage intake in low-income parents and their children also noted the association between the parent role of gatekeeper and food choices in the home ${ }^{(15)}$. Our results suggest that agreement between parental report of their views on the BAQ-HH and their report of children's health habits be further explored.

In addition, responses from the parents in this sample demonstrated overall trends and differences of interest for working in a community setting. The high level of agreement on all knowledge items may reflect parents' recall of Head Start programming about the importance of food and physical activity in the home ${ }^{(18)}$. On the other hand, attitude-related responses indicated parents had concerns about issues such as parental control of feeding and access to safe areas for physical activity. As noted by Vaughn and Waldrop ${ }^{(14)}$, parents play a key role in establishing children's habits in early childhood. Responses in the three areas of the BAQ-HH may inform obesity prevention efforts directed at parents. For example, responses on the BAQ-HH reflected parent report about frequency of decisions on children's portion sizes and healthy food choices, with fathers doing so less often than mothers (scores averaging about 4.3 and 4.8 respectively, indicating responses of 'often' to 'very often').

In other areas of the BAQ-HH, groups within the sample responded differently. Higher averages on items representing concerns by Hispanic parents indicated greater anxiety about their children's eating and physical activity habits. This may reflect trends noted in population studies, wherein there is great prevalence of overweight status $^{(2,3)}$ and greater needs. Referring back to research about socio-economic status, these parents may live in neighbourhoods in which they feel unsafe ${ }^{(40)}$ and thus leave their children unsupervised indoors if they have to work long hours or have more than one job. 
However, further information is needed as multiple influences may be at play with parents' attitudes and behaviours ${ }^{(19,20)}$. On average, parents reported a high frequency of communication behaviours on the BAQ-HH; e.g. talking about the value of healthy food, physical activity and pushing outdoor play. In comparison, parent interviews by Tandon et al. noted almost half of preschool children did not have parent-supervised outdoor playtime, despite the majority of respondents perceiving their neighbourhoods to be safe ${ }^{(41)}$. In both studies, parents' background was related to trends in time outdoors; however, findings of the two studies differed. From the parent interviews, both Hispanic ethnicity and parent schooling above high school level were associated with being less likely to take their children outside to play in Tandon et al.'s study ${ }^{(41)}$. In contrast, while our Hispanic parents trended to report greater levels of concern, the frequency of positive communication behaviours was reported to be high. When using the BAQ-HH with future community-based programming, differences in individual parent responses may be of more interest.

Other BAQ-HH observations in the present study included differences of interest based on ethnicity of respondents. As shown in Table 7, the attitude and behaviour scales were significantly higher for Hispanic parents. Population trends indicate that compared with their Caucasian counterparts, Hispanic children are at higher risk for overweight and obesity. An assessment of a parent education programme in Head Start centres sampled parents of pre-school children who were predominantly Latino of Mexican American origin, and found the importance of increasing parents' motivation and providing guidelines for home practices according to healthy guidelines ${ }^{(42)}$. In our research, higher mean attitude scores - reflective of higher levels of greater concern were seen in the Hispanic respondents.

While the present study had a good response rate and a mix of people that was fairly representative of the population, some limitations can be noted. Teachers and staff in the school setting administered the questionnaire and reasons for non-response were not recorded. If parents felt rushed for time, their quick responses may have contributed to the high levels of agreement with the knowledge items. Also, further study with the BAQ-HH as a pre/post measure with parents of pre-school children involved in health promotion programming, in conjunction with additional parental input, could provide further evidence for the validity of this measure.

\section{Conclusions}

Results from the present study provide validity evidence of scores from the BAQ-HH as a measure of parents' nutrition and physical activities for their family. Responses on the BAQ-HH related to other variables measured in the current cross-sectional survey of potential relevance indicate response trends that could assist health programming. As exemplified by the higher levels of concern on the attitude scale, individuals may benefit from interventions that move beyond general information for health promotion. While these results highlight differing response patterns among diverse samples, they also show potential benefits from working with community groups to identify relevant and language-appropriate health promotion material to meet parents' needs. The BAQ-HH may assist programme planners assess parents' perspectives about different content areas within the home environment, from role modelling and food rules to food availability and accessibility, and inform planning and monitoring of education interventions.

\section{Acknowledgements}

Sources of funding: This research received no specific grant from any funding agency in the public, commercial or not-for-profit sectors. Conflicts of interest: The authors have no conflicts of interest to report. Authors' contributions: Each author contributed to the study design, data collection and analysis, and manuscript preparation; each author approved the contents of the submitted manuscript. Acknowledgments: The authors appreciate the support of Northern Illinois University graduate students and Activate Elgin community coalition members who participated in the instrument design process; the administrators, staff and parents of the Two Rivers Head Start Agency who completed data collection with the BAQ-HH; and the Language Access to Healthcare, Interpreting \& Translation Services at Provena Mercy Medical Center (Aurora, IL, USA) who completed translation of the BAQ-HH.

\section{References}

1. Ogden CL \& Carroll MD (2010) Prevalence of obesity among children and adolescents: United States trends 1963-1965 through 2007-2009. http://www.cdc.gov/nchs/ data/hestat/obesity_child_07_08/obesity_child_07_08.pdf (accessed December 2012).

2. Ogden CL, Carroll MD, Curtin LR et al. (2010) Prevalence of high body mass index in US children and adolescents, 2007-2008. JAMA 303, 242-249.

3. Centers for Disease Control and Prevention (2011) Obesity rates among low-income preschool children. http://www.cdc.gov/obesity/childhood/data.html (accessed December 2012).

4. Lobstein T, Baur LA \& Jackson-Leach R (2010) The childhood obesity epidemic. In Preventing Childhood Obesity: Evidence Policy and Practice, pp. 3-14 [E Waters, BA Swinburn, JC Seidell et al., editors]. Oxford: Blackwell Publishing.

5. Janssen I, Craig W, Boyce W et al. (2004) Associations between overweight and obesity with bullying behaviors in school-aged children. Pediatrics 113, 1187-1194.

6. Dietz W (2004) Overweight in childhood and adolescence. $N$ Engl J Med 350, 855-857. 
7. Freedman DS, Khan LK, Dietz WH et al. (2001) Relationship of childhood obesity to coronary heart disease risk factors in adulthood: The Bogalusa Heart Study. Pediatrics 108, 712-718.

8. Ben-Shlomo Y \& Kuh D (2002) A life course approach to chronic disease epidemiology: conceptual models, empirical challenges and interdisciplinary perspectives. Int J Epidemiol 31, 285-293.

9. Lake A, Townshend TG \& Alvanides S (2010) Obesogenic Environments. Oxford: Wiley-Blackwell Publishing.

10. Faith MS, Van Horn L, Appel LJ et al. (2012) Evaluating parents and caregivers as 'agents of change' for treating obese children: evidence for parent behavior change strategies and research gaps: a scientific statement from the American Heart Association. Circulation 125, 1186-1207.

11. Birch LL \& Fisher JO (1998) Development of eating behaviors among children and adolescents. Pediatrics 101, 539-549.

12. Golan M \& Crow S (2004) Parents are key players in the prevention and treatment of weight-related problems. Nutr Rev 62, 39-50.

13. Davison KK \& Birch LL (2001) Childhood overweight: a contextual model and recommendations for future research. Obes Rev 2, 159-171.

14. Vaughn K \& Waldrop J (2007) Parent education key to beating early childhood obesity. Nurs Pract 32, 36-41.

15. Pinard CA, Davy BM \& Estabrooks PA (2011) Beverage intake in low-income parent-child dyads. Eat Behav 12, 313-316.

16. Henderson AT \& Mapp KL (editors) (2002) A New Wave of Evidence: The Impact of School, Family, and Community Connections on Student Achievement. Annual Synthesis 2002. Austin, TX: National Center for Family and Community Connections with Schools; available at http://www. sedl.org/connections/resources/evidence.pdf

17. Larson N, Ward D, Benjamin Neelon S et al. (2011) What role can child-care settings play in obesity prevention? A review of the evidence and call for research efforts. $J \mathrm{Am}$ Diet Assoc 111, 1343-1362.

18. Gooze RA, Hughes CC, Finkelstein DM et al. (2010) Reaching staff, parents, and community partners to prevent childhood obesity in Head Start, 2008. Prev Chronic Dis 7, A54.

19. Baranowski T, Cullen KW, Nicklas $T$ et al. (2003) Are current health behavioral change models helpful in guiding prevention of weight gain efforts? Obes Res 11, Suppl., 23S-43S.

20. Contento I (editor) (2011) An overview of nutrition education: facilitating why and how to take action. In Nutrition Education: Linking Research, Theory, and Practice, 2nd ed, pp. 60-61. Sudbury, MA: Jones \& Bartlett Publishers, LLC.

21. Variyam JN, Blaylock J \& Smallwood DM (1996) Modelling nutrition knowledge, attitudes, and diet-disease awareness: the case of dietary fibre. Stat Med 15, 23-35.

22. Misra R (2007) Knowledge, attitudes, and label use among college students. J Am Diet Assoc 107, 2130-2134.

23. Escalante-Guerrero CS, De La Roca-Chiapas JM \& Macias-Cervantes MH (2012) Knowledge, attitudes, and behavior concerning nutrition and physical activity in Mexican children. Am J Health Bev 36, 424-431.

24. Rimal RN (2000) Closing the knowledge-behavior gap in health promotion: the mediating role of self-efficacy. Health Commun 12, 219-237.

25. Wall D, Least C, Gromis J et al. (2012) Nutrition education intervention improves vegetable-related attitude, selfefficacy, preference, and knowledge of fourth-grade students. J Sch Health 82, 37-43.
26. Pinard CA, Yaroch AL, Hart MH et al. (2011) Measures of the home environment related to childhood obesity: a systematic review. Public Health Nutr (Epublication ahead of print version).

27. US Department of Health and Human Services, Administration for Children \& Families (2012) Office of Head Start. http://www.acf.hhs.gov/programs/ohs/ (accessed December 2012).

28. Makoul G, Krupat E \& Chang C-H (2007) Measuring patient views of physician communication skills: development and testing of the Communication Assessment Tool. Patient Educ Couns 67, 333-342.

29. Birch LL, Fisher JO, Grimm-Thomas K et al. (2001) Confirmatory factor analysis of the Child Feeding Questionnaire: a measure of parental attitudes, beliefs and practices about child feeding and obesity proneness. Appetite 36, 201-210.

30. Moag-Stahlberg A, Miles A \& Marcella M (2003) What kids say they do and how parents think kids are doing: The ADAF/Knowledge Networks 2003 Family Nutrition and Physical Activity Study. J Am Diet Assoc 103, 1541-1546.

31. Hardus PM, Van Vurren CL, Crawford D et al. (2003) Public perceptions of the causes and prevention of obesity among primary school children. Int J Obes Relat Metab Disord 27, $1465-1471$.

32. Reddan J, Wahlstrom K \& Reicks M (2002) Children's perceived benefits and barriers in relation to eating breakfast in schools with and without universal school breakfast. J Nutr Educ Behav 34, 47-52.

33. Bodhani AR (2006) Parenting, home environment, and child obesity: a survey of parents and children attending a pediatric clinic. Master of Public Health Thesis, East Tennessee State University; available at http://etd-submit. etsu.edu/etd/theses/available/etd-0714106-185732/

34. National Heart, Lung, and Blood Institute (2007) Ways to Enhance Children's Activity \& Nutrition (We Can!) Parent questionnaire. http://www.nhlbi.nih.gov/health/public/heart/ obesity/wecan/downloads/progsummary.pdf (accessed December 2012).

35. Ward D (2007) Parent survey on child obesity risk. Smart Spot - Kids' Health Quiz. http://www.smartspot.com (accessed September 2007).

36. Rao G (2008) Childhood obesity: highlights of AMA expert committee recommendations. Am Fam Physician $\mathbf{7 8}$, 56-63, 65-66.

37. O'Connor BP (2000) SPSS and SAS programs for determining the number of components using parallel analysis and Velicer's MAP test. Behav Res Methods Instrum Comp 32, 396-402.

38. Hooper D, Coughlan J \& Mullen MR (2008) Structural equation modelling: guidelines for determining model fit. Electronic J Bus Res Methods 6, 53-60.

39. Hu LT \& Bentler PM (1999) Cutoff criteria for fit indexes in covariance structure analysis: conventional criteria vs. new alternatives. Struct Equ Modeling 6, 1-55.

40. Food and Research Action Center (2010) Why Low Income and Food insecure People are Vulnerable to Overweight and Obesity. http://frac.org/initiatives/hunger-and-obesity/ why-are-low-income-and-food-insecure-people-vulnerableto-obesity/ (accessed December 2012).

41. Tandon PS, Zhou C \& Christakis DA (2012) Frequency of parent-supervised outdoor play of US preschool children. Arch Pediatr Adolesc Med 166, 707-712.

42. Winter SM \& Sass DA (2011) Healthy \& ready to learn: examining the efficacy of an early approach to obesity prevention and school readiness. J Res Child Educ 25, 304-325. 